\title{
nature
}

4 March 2004 Volume 428 Issue no 6978

\section{In no one's best interest}

The latest twist in Britain's ongoing scare about the safety of a widely used vaccine has brought researchers' conflicts of interest to public attention. Unfortunately, the affair has promoted a simplistic view of this complex issue.

L ike it or not, we live in a world in which Mammon and science can walk hand-in-hand. Researchers often have a financial interest in the projects on which they work - they may own shares in a spin-off company, for instance, or hold a patent on a key discovery.

Dealing with these conflicts is one of the thorniest issues facing today's journal editors. Many journals, including the Nature journals, have taken the view that disclosure is the best policy — and ask their authors to complete conflict-of-interest statements.

Medical journals have blazed the trail in tackling this difficult issue. And at first glance, recent statements from The Lancet seem to continue this trend. When the journal was told that The Sunday Times newspaper had uncovered an undeclared conflict of interest relating to a paper it had published in 1998, its editors launched an immediate investigation. Two days later, they said that the paper should not have been published in its original form (see Nature 427, 765; 2004).

The paper in question described a novel syndrome combining gut inflammation and forms of autism (A. J. Wakefield et al. Lancet 351, 637-641; 1998). More controversially, it speculated that the combined measles, mumps and rubella (MMR) vaccine might be to blame - a link stressed in subsequent statements to the media by lead author Andrew Wakefield. This placed The Lancet at the centre of a storm. Worried parents have shunned the MMR vaccine. The medical establishment, citing a lack of evidence from epidemiological studies, has denounced Wakefield and the controversial paper.

The latest development is the allegation that Wakefield had accepted funding under Britain's legal-aid system to perform another study to investigate the possible link between the MMR vaccine and autism on behalf of parents who were considering suing for damages. Had they known this, say The Lancet's editors, they would have asked Wakefield to change the part of the paper that suggested there was a link.
Is this a reasonable response to the new allegation? Well, that's debatable. The link between MMR and autism was always speculative in the extreme, and many editors would have demanded its exclusion from the paper irrespective of any alleged conflict of interest. But The Lancet routinely publishes papers by employees of drug companies and by researchers who are paid to testify in legal cases relating to their work. Wakefield's speculation about MMR was not well grounded, and many experts in public health will be delighted that this prestigious journal is now distancing itself from this part of his paper. It's unclear, however, whether Wakefield was any more compromised by conflicting interests than are many other of The Lancet's authors.

Then there is the question of whether Wakefield really did hide his alleged conflict. He made no statement when submitting the original paper, but in correspondence published in The Lancet some two months after the original publication, he acknowledged evaluating a few children on behalf of the Legal Aid Board. Wakefield did not state

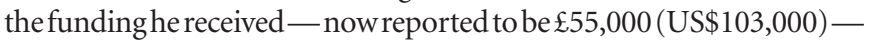
and there is some ambiguity as to whether he was referring to patients in the controversial paper. But his actions hardly seem those of someone determined to conceal a fatal conflict. And his belated disclosure did not prompt any public reaction from The Lancet's editors at the time.

The problem is that many observers of The Lancet's disavowal of Wakefield's speculation about MMR in the face of a journalist's inquiry will now assume that researchers' conflicts of interest inevitably undermine their integrity. But if these conflicts are managed properly, and disclosed, this needn't be the case. Few journals are in a position to aggressively police their conflict-of-interest policies, so further allegations are inevitable. It's to be hoped that the next editor to feel the heat does a better job of explaining the link between the alleged conflict and the validity of the paper concerned.

\section{Ending the pain in Spain}

\section{Whoever wins the Spanish general election must deliver on their vague promises about supporting science.}

$\mathrm{n}$ the run-up to Spain's general election, public funding of research has made a rare foray into the headlines. Politicians from across the spectrum have voiced their support for the country's scientists, following the release of a 'state pact for science' endorsed by the Spanish Society of Molecular Biology and Biochemistry.

The document, signed by 11 of Spain's leading scientists, calls for a doubling of the proportion of gross domestic product spent on research and development by 2010. It demands a similar expansion of the country's scientific workforce.

Both major parties say that they back these moves. But will the victors in the 14 March poll make science a lasting priority? They should have every incentive to do so. A large reservoir of talent exists - young Spanish researchers are highly welcome guests at labs throughout Europe and North America. But lack of political interest and Spanish bureaucracy have prevented most of them from returning to contribute to Spain's development as a scientific power.

Spanish politicians should wake up to the role science can play in stimulating the economy. And they should look to emulate the few programmes and centres that point to a future in which Spanish science no longer punches below its weight.

Over the past three years, a programme named after Spain's first Nobel laureate, the neuroscientist Santiago Ramón y Cajal, has repatriated almost 2,000 of Spain's diaspora of postdocs. It should be expanded. But if this programme is to bear fruit, the returnees need to be given a working environment where openness, free movement of staff and stiff competition for funds are the norm. Unfortunately, this is not the case in Spanish academia.

In Madrid, however, the National Center for Cancer Research, or CNIO, a private foundation owned by the health ministry, has in just six years gained an international reputation that most of Spain's universities and institutes can only dream of. Bureaucracy is minimal, and scientists can be recruited at any time. In Barcelona, the regional Catalan government has set up institutes along similar lines. These successful experiments should be repeated on a much broader scale. 